\title{
Clinical and biochemical study of D-serine metabolism among schizophrenia patients
}

\author{
This article was published in the following Dove Press journal: \\ Neuropsychiatric Disease and Treatment \\ 10 April 2017 \\ Number of times this article has been viewed
}

\author{
Hamdy N El-Tallawy' \\ Tahia H Saleem ${ }^{2}$ \\ Abdallah MAA El-Ebidi ${ }^{3}$ \\ Mohammed H Hassan ${ }^{4}$ \\ Romany H Gabra' \\ Wafaa MA Farghaly' \\ Nagwa Abo El-Maali ${ }^{5}$ \\ Hoda S Sherkawy ${ }^{3}$ \\ 'Department of Neuropsychiatry, \\ ${ }^{2}$ Department of Medical Biochemistry \\ and Molecular Biology, Faculty of \\ Medicine, Assiut University, Assiut, \\ ${ }^{3}$ Department of Medical Biochemistry \\ and Molecular Biology, Faculty of \\ Medicine, Aswan University, Aswan \\ ${ }^{4}$ Department of Medical Biochemistry \\ and Molecular Biology, Qena Faculty \\ of Medicine, South Valley University, \\ Qena, ${ }^{5}$ Department of Chemistry, \\ Faculty of Science, Assiut University, \\ Assiut, Egypt
}

\begin{abstract}
Background: Schizophrenia is a typical $N$-methyl-D-aspartate receptor (NMDA-R) hypofunction disorder. Decreased D-serine (D-Ser) levels in the periphery occur in schizophrenia and may reflect decreased availability of D-Ser to activate NMDA-R in the brain.

Objective: The objective of this study was to investigate the role of D-Ser metabolism in the pathogenesis of schizophrenia via biochemical assays and correlates, the serum level of D-Ser, D-serine racemase (SR) (responsible for its formation from L-serine [L-Ser]) and D-amino acid oxidase (DAAO) (responsible for its catabolism), among different clinical types of schizophrenia patients.
\end{abstract}

Patients and methods: This cross-sectional case-control study was carried out on 100 patients and 50 controls. They were recruited from the outpatients' psychiatric unit of the Neuropsychiatric Department of Assiut University Hospital, Upper Egypt. The type of schizophrenia was determined according to the Diagnostic and Statistical Manual of Mental Disorders, Fourth Edition (DSM-IV), while the severity of schizophrenia was determined according to the Diagnostic and Statistical Manual of Mental Disorders, Fifth Edition (DSM-5). Serum D-Ser levels were estimated using high-performance liquid chromatography (HPLC), while serum SR and DAAO were measured using commercially available enzyme-linked immunosorbent assay kits.

Results: There were significantly lower mean serum levels of D-Ser and SR and significantly higher mean serum levels of DAAO ( $P$-value $<0.01$ for each) among schizophrenia patients when compared with the control group. Paranoid schizophrenia had the highest frequency, with a significantly lower serum levels of D-Ser and SR in the residual type and significantly higher serum levels of DAAO in undifferentiated and catatonic types. Combined receiveroperating characteristic curve for serum D-Ser, SR and DAAO indicated that the best serum level cutoff points at which schizophrenia manifestations started to appear were $\leq 61.4 \mathrm{mg} / \mathrm{L}$ for D-Ser, $\leq 15.5 \mathrm{pg} / \mathrm{mL}$ for SR and $>35.6 \mathrm{pg} / \mathrm{mL}$ for DAAO.

Conclusion: The present study confirms that disturbed D-Ser metabolism could be implicated in the pathogenesis of schizophrenia.

Keywords: D-serine, serine racemase, D-amino acid oxidase, schizophrenia, HPLC

\section{Introduction}

Schizophrenia is a complex and multifaceted neuropsychiatric disorder characterized by delusions, hallucinations, passivity phenomena, disordered thought process, disorganized behavior and progressive cognitive deficits. ${ }^{1}$ According to the World Health Organization, the global prevalence of schizophrenia is $\sim 3.8 \%-8.4 \%{ }^{2}$ Schizophrenia remains a leading cause of disability worldwide. ${ }^{3}$ Schizophrenia symptoms can be categorized as positive and negative; positive symptoms include delusions and hallucinations, whereas negative symptoms include anhedonia, asociality, alogia, avolition
Correspondence: Romany H Gabra Department of Neuropsychiatry, Faculty of Medicine, Assiut University, PO Box 7I5I5, Assiut, Egypt Tel +20 I2 89262727 Email romany_hosny27@hotmail.com 
and blunted emotional response. In addition, schizophrenia patients suffer from varying degrees of cognitive deficit with impairments in attention, memory and executive functions. ${ }^{4}$

Schizophrenia is a chronic condition that generally appears in late adolescence or early adulthood. Several data suggest that hypofunction of glutamatergic neurotransmission, via the $N$-methyl-D-aspartate receptor (NMDA-R), plays a crucial role in the pathophysiology of schizophrenia. ${ }^{5,6}$ D-serine (D-Ser), an important coagonist at the NMDA-R, is integral to neurotransmission via NMDA signaling throughout development. ${ }^{7}$ Several clinical studies have demonstrated a disturbed NMDA-R neurotransmission, due to decreased D-Ser levels, as a main cause of the pathophysiology of schizophrenia. ${ }^{8}$ First, many reports have shown lower levels of D-Ser in the blood, cerebrospinal fluid (CSF) and postmortem brain tissue from patients with schizophrenia, relative to normal controls. ${ }^{9}$ Second, treatment with D-Ser proved to be beneficial for alleviating several symptoms associated with schizophrenia. ${ }^{10}$ Although two meta-analysis studies supported the findings that D-Ser is effective in treating schizophrenia, ${ }^{11}$ D-Ser is not approved as a therapeutic drug for schizophrenia. Third, several studies showed an increase in mRNA expression and the activity of D-amino acid oxidase (DAAO), which metabolizes D-Ser, in postmortem brains of schizophrenic patients. ${ }^{12}$

Despite the growing amount of data supporting the role of D-Ser in the pathophysiology of schizophrenia, some reports show no evidence of decreased D-Ser in the schizophrenia brain. ${ }^{13}$

D-Ser is synthesized from L-serine (L-Ser) via one enzymatic step catalyzed by the enzyme serine racemase (SR). ${ }^{14}$ L-Ser is biosynthesized from 3-phosphoglycerate, a glucose metabolite, via three enzymatic steps catalyzed by 3-phosphoglycerate dehydrogenase (PHGDH), phosphoserine aminotransferase 1 (PSAT1) and phosphoserine phosphatase (PSP). ${ }^{15}$

D-Ser can be degraded by DAAO. ${ }^{16,17} \mathrm{D}-\mathrm{Ser}$ is an endogenous NMDAR co-agonist, ${ }^{18}$ and it is reported that the associated metabolic pathways can participate in schizophrenia pathophysiology. ${ }^{19}$

Based on the assumption that SR and DAAO are key molecules in the pathophysiology of schizophrenia, ${ }^{20}$ the present study was carried out to further clarify the pattern of metabolism of D-Ser in schizophrenia and if its serum level is affected by the clinical type of the schizophrenia or the duration of antipsychotic therapy. This might open the field to new therapeutic strategies for such patients.

\section{Patients and methods Study design}

This cross-sectional case-control study was carried out on 100 patients ( 38 females and 62 males). Their mean age was $31.0 \pm 8.7$ years, with the mean duration of schizophrenia of 5.99 \pm 4.90 years. Apparently, 50 healthy age- and sexmatched subjects (20 females and 30 males) were selected as a control group (they were selected from paramedical volunteers' personnel). The total duration of the study was 12 months, from April 1, 2015, to March 31, 2016. Prior to the initiation of the study, every patient was informed about the aim of the study and gave a written consent. Patients were recruited from the outpatients' Psychiatric Unit of the Neuropsychiatric Department of Assiut University Hospital, Upper Egypt, after approval of the university ethics committee.

\section{Data collection}

Detailed history for all included patients was taken, including personal history (age, sex, duration of illness); family history of psychiatric disorders, including schizophrenia, mood disorder and anxiety disorder; and therapeutic history (duration of antipsychotic intake and if there was associated electroconvulsive therapy [ECT]). Thorough neurological examination was carried out. The type of schizophrenia according to the Diagnostic and Statistical Manual of Mental Disorders, Fourth Edition (DSM-IV), and the severity of schizophrenia according to the Diagnostic and Statistical Manual of Mental Disorders, Fifth Edition (DSM-5), were determined.

\section{Methodology}

Patients' blood samples $(5 \mathrm{cc})$ were taken from antecubital veins. Serum separator tubes were used, and samples were allowed to be clotted for 30 minutes before centrifugation for 15 minutes at $1,000 \mathrm{rpm}$. Serum of each sample was transferred and divided into three aliquots using $1 \mathrm{~mL}$ cryotubes and stored at $-20^{\circ} \mathrm{C}$ till the time of analysis. All samples were measured in a single assay to avoid repeated freeze-thaw cycles.

Serum D-Ser levels were estimated using an Agilent HighPerformance Liquid Chromatography (HPLC) 1200 Series system (Agilent Technologies, Santa Clara, CA, USA) consisting of degasser, quaternary pump, autosampler, thermostated column department and photodiode array detector, which were all controlled by Agilent ChemStation. A Zorbax Extend-C18 column $(150 \times 4.6 \mathrm{~mm}$ ID $\times 5 \mu \mathrm{m}$ particle size $)$ was used for determination. The analysis was done according to the following chromatographic conditions: $0.2 \mathrm{~mL}$ from 
the sample added to $0.2 \mathrm{~mL}$ concentrated hydrochloric acid (Conc HCL) and centrifugation at 140,000 revolutions per minute (rpm) at $4^{\circ} \mathrm{C}$ for $15-20$ minutes. Then, $0.02 \mathrm{~mL}$ from the clear supernatant was taken and mixed with 0.02 orthophthalaldehyde (OPA) and $0.16 \mathrm{~mL}$ Milli-Q water. Then, the mixture was injected on the high-performance liquid chromatography with diode-array detector (HPLC-DAD) mobile phase: dibasic phosphate buffer $0.05 \mathrm{M}$ at $\mathrm{pH}=6.5$, flow rate: $1.5 \mathrm{~mL} / \mathrm{min}$ and wavelength: $338 \mathrm{~nm}$.

A commercially available enzyme-linked immunosorbent assay (ELISA) assay kits were used for measurement of the following biochemical parameters, according to their manufacturer protocol (using ELISA Multiskan EX Microplate Photometer [STAT FAX-2100; Thermo Scientific, Palm City, FL, USA]):

1. serum SR levels using kit supplied by Glory Science Co., Ltd (Del Rio, TX, USA) and

2. serum DAAO levels using kit provided by Glory Science Co., Ltd.

\section{Statistical analysis}

The data were tested for normality using the AndersonDarling test and for homogeneity variances prior to further statistical analysis. Categorical variables were described by number and percent (n, \%), whereas continuous variables were described by mean and standard deviation (mean, SD). Chi-square test and Fisher's exact test were used to compare categorical variables, while Student's $t$-test and analysis of variance (ANOVA) were used to compare continuous quantitative variables of parametric data. Pearson correlation coefficients were used to assess the correlation between continuous variables. A two-tailed test was considered significant when $P$ was $<0.05$ and highly significant when $P$ was $<0.01$. All analyses were performed using the IBM SPSS version 20.0 software (IBM Corporation, Armonk, NY, USA).

\section{Results}

The baseline characteristics of the studied patients are presented in Table 1.

Table 2 lists the clinical data of the studied patients. Hallucination was the most frequent symptom ( $85 \%)$, while the negative symptoms were the least frequent symptoms (7\%). According to DSM-5, 85\% of patients had severe schizophrenia. According to $D S M-I V$, paranoid schizophrenia had the highest frequency (46\%).

The mean serum levels of the studied biochemical parameters (D-Ser, SR and DAAO) are presented in Table 3 and Figure 1, which reveal significantly lower serum levels of
Table I Baseline characteristics of the studied patients

\begin{tabular}{|c|c|c|c|}
\hline Variables & $\begin{array}{l}\text { Patients group } \\
(n=100)\end{array}$ & $\begin{array}{l}\text { Control group } \\
(n=50)\end{array}$ & $P$-value \\
\hline Age & & & 0.706 \\
\hline Range & $17-64$ & $17-65$ & \\
\hline Mean \pm SD & $31.0 \pm 8.7$ & $31.6 \pm 10.0$ & \\
\hline Sex & & & 0.225 \\
\hline Male, n (\%) & $36(62)$ & $36(72)$ & \\
\hline Female, n (\%) & $38(38)$ & $14(28)$ & \\
\hline \multirow{2}{*}{$\begin{array}{l}\text { Duration of illness } \\
\text { (years) }\end{array}$} & \multirow{2}{*}{$\begin{array}{l}\text { Total } \\
(n=100)\end{array}$} & Sex & \\
\hline & & $\begin{array}{l}\text { Males } \\
(n=62)\end{array}$ & $\begin{array}{l}\text { Females } \\
(n=38)\end{array}$ \\
\hline Mean \pm SD & $5.99 \pm 4.90$ & $5.66 \pm 4.4 I$ & $6.53 \pm 5.63$ \\
\hline $0.17-<5$ years, $n(\%)$ & $54(54.0)$ & $35(64.8)$ & $19(35.2)$ \\
\hline $5-<10$ years, $n(\%)$ & $21(21.0)$ & $12(57.1)$ & $9(42.9)$ \\
\hline$\geq 10$ years, $n(\%)$ & $25(25.0)$ & $15(60.0)$ & $10(40.0)$ \\
\hline \multicolumn{4}{|c|}{ Therapeutic history, n (\%) } \\
\hline Antipsychotics & $100(100)$ & $66(66)$ & $34(34)$ \\
\hline Antipsychotics + ECT & $50(50)$ & $33(66)$ & $17(34)$ \\
\hline $\begin{array}{l}\text { Family history of } \\
\text { schizophrenia or } \\
\text { mental illness, } n(\%)\end{array}$ & $26(26)$ & $16(61.5)$ & $10(38.5)$ \\
\hline
\end{tabular}

Abbreviations: SD, standard deviation; ECT, electroconvulsive therapy.

D-Ser and SR and significantly higher serum levels of DAAO in schizophrenia patients compared with the control.

There was no statistically significant difference in the studied biochemical parameters (D-Ser, SR and DAAO) of the studied schizophrenic patients with regard to sex, duration of antipsychotic therapy and various age groups.

There was a positive correlation between serum D-Ser and SR, whereas a negative correlation between serum D-Ser and

Table 2 Clinical data of the studied patients

\begin{tabular}{|c|c|c|c|}
\hline Variables & $\begin{array}{l}\text { Total } \\
(n=100)\end{array}$ & Males & Females \\
\hline \multicolumn{4}{|l|}{ Symptomatology } \\
\hline \multicolumn{4}{|l|}{ Positive symptoms, n (\%) } \\
\hline Delusion & $79(79)$ & $49(62)$ & $30(38)$ \\
\hline Hallucination & $85(85)$ & $54(63.5)$ & $31(36.5)$ \\
\hline Negative symptoms, n (\%) & $7(7)$ & $5(7 I)$ & $2(29)$ \\
\hline Associated mood symptoms, $\mathrm{n}(\%)$ & $63(63)$ & $41(65)$ & $22(35)$ \\
\hline Manic symptoms & $40(40)$ & $28(70)$ & $15(30)$ \\
\hline Depressive symptoms & $23(23)$ & $16(69.5)$ & $7(30.5)$ \\
\hline \multicolumn{4}{|c|}{ Degree of severity of schizophrenia according to DSM-5, n (\%) } \\
\hline Moderate & $15(15.0)$ & $9(60)$ & $6(40)$ \\
\hline Severe & $85(85.0)$ & $53(62)$ & $32(38)$ \\
\hline \multicolumn{4}{|c|}{ Clinical types of schizophrenia patients according to DSM-IV, $\mathrm{n}(\%)$} \\
\hline Paranoid & $46(46)$ & $25(54)$ & $21(46)$ \\
\hline Disorganized & $14(14)$ & $8(57)$ & $6(43)$ \\
\hline Catatonic & $8(8)$ & $2(25)$ & $6(75)$ \\
\hline Undifferentiated & $24(24)$ & $20(83)$ & $4(17)$ \\
\hline Residual & $8(8)$ & $6(75)$ & $2(25)$ \\
\hline
\end{tabular}

Abbreviations: DSM-5, Diagnostic and Statistical Manual of Mental Disorders, Fifth Edition; DSM-IV, Diagnostic and Statistical Manual of Mental Disorders, Fourth Edition. 
Table 3 Mean \pm SEM of the serum levels of D-Ser, SR and DAAO in schizophrenia patients compared with the control group

\begin{tabular}{llll}
\hline Variables & Patients & Control & P-value \\
\hline D-Ser $(\mathrm{mg} / \mathrm{L})$ & $6.792 \pm 0.88$ & $\mid 44.068 \pm 6.63$ & $0.00 I^{* *}$ \\
SR $(\mathrm{pg} / \mathrm{mL})$ & $9.362 \pm 0.37$ & $61.84 I \pm 8.44$ & $0.00 I^{* *}$ \\
DAAO $(\mathrm{pg} / \mathrm{mL})$ & $60.466 \pm 5.37$ & $26.526 \pm 1.10$ & $0.00 I^{* *}$ \\
\hline
\end{tabular}

Note: **Statistically significant difference $(P<0.01)$.

Abbreviations: SEM, standard error of the mean; D-Ser, D-serine; SR, D-serine racemase; DAAO, D-amino acid oxidase.

DAAO and between SR and DAAO was found, as shown in Figures 2-4.

There was a non-significant difference in the serum levels of the studied biochemical parameters between moderate and severe schizophrenia. Significant highest serum levels of D-Ser and SR in the residual type and significant highest serum levels of DAAO in the disorganized type followed by the paranoid type were found (Table 4). Combined receiveroperating characteristic (ROC) curve for serum D-Ser, SR and DAAO is presented in Table 5. The serum level cutoff points were $\leq 61.4 \mathrm{mg} / \mathrm{L}$ for D-Ser and $\leq 15.5 \mathrm{pg} / \mathrm{mL}$ for SR at a sensitivity of $100 \%$ and a specificity of $100 \%$ for both. The serum level cutoff point for DAAO was $>35.6 \mathrm{pg} / \mathrm{mL}$ at a sensitivity of $67 \%$ and a specificity of $88 \%$.

\section{Discussion}

Schizophrenia is a common and devastating mental illness. ${ }^{2}$ It is a clinically and etiologically heterogeneous mental disorder that is characterized by delusions, hallucinations and bizarre behaviors. ${ }^{21}$

In the present study, the male:female ratio of schizophrenic patients was 2:1. This finding is in agreement with previous studies that reported a higher prevalence of schizophrenia among males than among females. ${ }^{22-24}$

All the included patients (100\%) were on antipsychotic drugs, and $50 \%$ of them were on "ECT" in addition to the

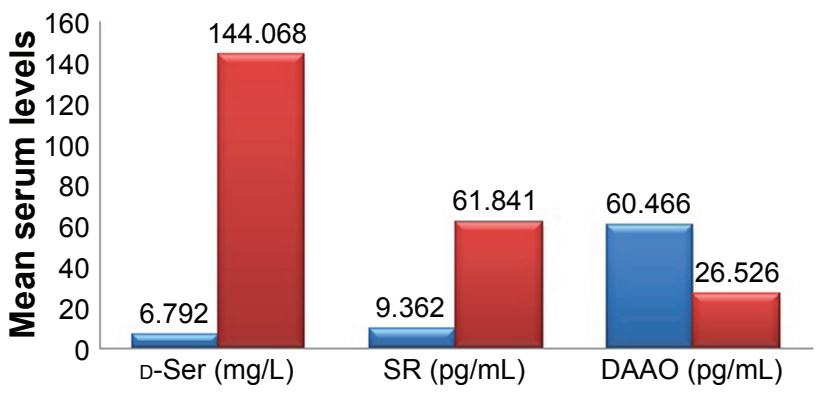

Figure I Comparison between the mean serum levels of D-Ser, SR and DAAO among schizophrenia patients versus the control group.

Abbreviations: D-Ser, D-serine; SR, D-serine racemase; DAAO, D-amino acid oxidase.

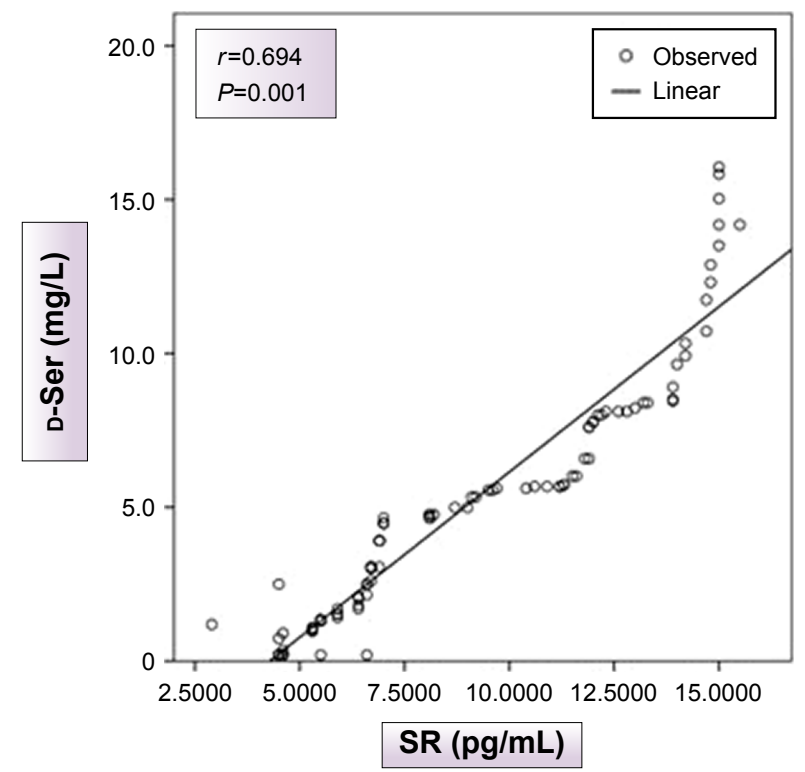

Figure 2 Correlation of the serum levels of D-Ser and SR among schizophrenia patients showing a positive correlation.

Abbreviations: D-Ser, D-serine; SR, D-serine racemase.

antipsychotic medications. In accordance, a study done by Pawełczyk et $\mathrm{al}^{25}$ reported that approximately half of the included patients with schizophrenia in their study were on ECT together with antipsychotics.

The majority of our schizophrenic patient sample was of severe type (85\%), according to DSM-5, as mild and moderate cases usually do not prefer admission to a mental hospital and prefer treatment in outpatients clinic.

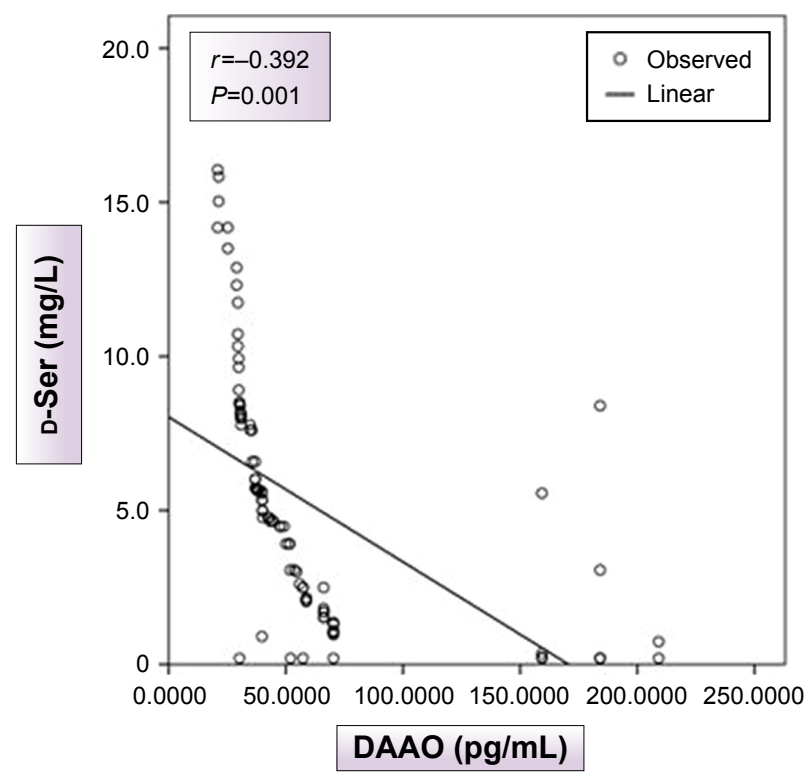

Figure 3 Correlation of the serum levels of D-Ser and DAAO among schizophrenia patients showing a negative correlation.

Abbreviations: D-Ser, D-serine; DAAO, D-amino acid oxidase. 


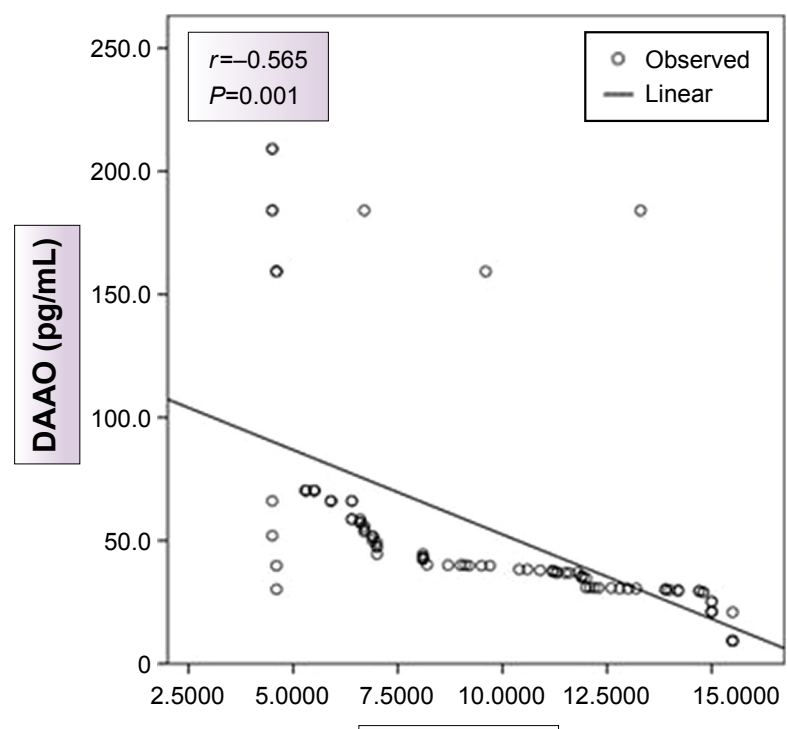

SR $(\mathrm{pg} / \mathrm{mL})$

Figure 4 Correlation of the serum levels of DAAO and SR among schizophrenia patients showing a negative correlation.

Abbreviations: DAAO, D-amino acid oxidase; SR, D-serine racemase.

This decreased D-Ser level in the periphery may reflect decreased availability of D-Ser to activate NMDA-Rs in the brain. ${ }^{26,27}$ Schizophrenia is a typical NMDAR hypofunction disorder. ${ }^{28}$ The present study revealed significantly lower serum levels of D-Ser among schizophrenia patients compared with the control group. In agreement with this finding, a study done by Hashimoto et $\mathrm{al}^{29}$ and Yamada et $\mathrm{al}^{30}$ reported lower serum levels of D-Ser in individuals

Table 4 Mean \pm SD of the serum levels of D-Ser, SR and DAAO in the studied schizophrenia patients according to the severity using DSM-5 and according to the clinical type using DSM-IV

\begin{tabular}{|c|c|c|c|}
\hline \multirow[t]{2}{*}{ Variables } & \multicolumn{2}{|c|}{$\begin{array}{l}\text { Degree of schizophrenia } \\
\text { according to DSM-5 }\end{array}$} & \multirow[t]{2}{*}{$P$-value } \\
\hline & Moderate & Severe & \\
\hline D-Ser (mg/L) & $5.67 \pm 8.8$ & $6.99 \pm 8.88$ & 0.595 \\
\hline $\mathrm{SR}(\mathrm{pg} / \mathrm{mL})$ & $8 \pm 4.04$ & $9.6 \pm 3.64$ & 0.125 \\
\hline DAAO (pg/mL) & $62.11 \pm 39.71$ & $60.18 \pm 55.96$ & 0.898 \\
\hline $\begin{array}{l}\text { Types of } \\
\text { schizophrenia } \\
\text { according to DSM-IV }\end{array}$ & $\begin{array}{l}\text { D-Ser } \\
(\mathrm{mg} / \mathrm{L})\end{array}$ & $\begin{array}{l}\text { SR } \\
(\mathrm{pg} / \mathrm{mL})\end{array}$ & $\begin{array}{l}\text { DAAO } \\
(\mathrm{pg} / \mathrm{mL})\end{array}$ \\
\hline Paranoid & $7.49 \pm 11.36$ & $9.07 \pm 3.82$ & $64.76 \pm 63.45$ \\
\hline Disorganized & $3.31 \pm 3.14$ & $7.39 \pm 3.13$ & $81.25 \pm 58.17$ \\
\hline Catatonic & $10.5 \pm 10.36$ & $11.69 \pm 2.32$ & $47.44 \pm 46.24$ \\
\hline Undifferentiated & $5.76 \pm 4.08$ & $9.68 \pm 3.42$ & $46.18 \pm 27.29$ \\
\hline Residual & $11.38 \pm 4.62$ & $|4 \pm 1.0|$ & $54.08 \pm 63.8$ \\
\hline$P$-value & $<0.001$ & $<0.001$ & $<0.001$ \\
\hline
\end{tabular}

Abbreviations: SD, standard deviation; D-Ser, D-serine; SR, D-serine racemase; DAAO, D-amino acid oxidase; DSM-5, Diagnostic and Statistical Manual of Mental Disorders, Fifth Edition; DSM-IV, Diagnostic and Statistical Manual of Mental Disorders, Fourth Edition.
Table 5 ROC curves of the serum levels of D-Ser, SR and DAAO for detection of the cutoff value of positive cases with schizophrenia

\begin{tabular}{lllllll}
\hline & AUC & Cutoff & Sensitivity & Specificity & PPV & NPV \\
\hline D-Ser $(\mathrm{mg} / \mathrm{L})$ & 1.0 & $\leq 61.4$ & 100.0 & 100.0 & 100.0 & 100.0 \\
SR $(\mathrm{pg} / \mathrm{mL})$ & 1.0 & $\leq 15.5$ & 100.0 & 100.0 & 100.0 & 100.0 \\
DAAO $(\mathrm{pg} / \mathrm{mL})$ & 0.833 & $>35.6$ & 67.0 & 88.0 & 91.8 & 57.1
\end{tabular}

Abbreviations: ROC, receiver-operating characteristic; D-Ser, D-serine; SR, D-serine racemase; DAAO, D-amino acid oxidase; AUC, area under the curve; PPV, positive predictive value; NPV, negative predictive value.

with schizophrenia compared with the healthy controls. Similarly, Mothet et al ${ }^{31}$ found that reduced levels of D-Ser reflect hypofunction of NMDA-Rs in patients with schizophrenia. On the contrary, other studies (Ohnuma and Arai, ${ }^{32}$ Brouwer et $\mathrm{al}^{33}$ and Ozeki et $\mathrm{al}^{24}$ ) found insignificant difference in the serum levels of D-Ser between the control and the schizophrenic patients.

Enhanced DAAO activity is a potential cause of reduced D-Ser and hence impaired NMDAR functioning in schizophrenia. ${ }^{34}$ The present study revealed significantly higher serum levels of DAAO among schizophrenia patients compared to the control group. Consistent with this finding, previous studies done by Chumakov et al, ${ }^{35}$ Boks et al, ${ }^{36}$ Madeira et $\mathrm{al}^{37}$ and Burnet et $\mathrm{a} \mathrm{l}^{38}$ found an increased DAAO activity and expression among patients with schizophrenia. D-Ser racemase is a pyridoxal-5'-phosphate (PLP)-dependent enzyme that catalyzes racemization of L-Ser to D-Ser. ${ }^{39}$ The present study revealed significantly lower serum levels of SR among schizophrenia patients compared with the control group. These results are in agreement with a study done by Yamada et $a{ }^{30}$ who reported that D-Ser in the blood may originate from the brain and that reduced serum levels of D-Ser in schizophrenia may reflect a decrease in the enzymatic activity of SR in the brains of schizophrenic patients.

Regarding the correlation between the studied biochemical parameters among the schizophrenia patients, the present study revealed a significant negative correlation between DAAO on one hand and both D-Ser and SR on the other hand. Moreover, there was a significant positive correlation between SR and D-Ser concentrations. These findings are in agreements with those reported by Calcia et al ${ }^{40}$ and Bendikov et al, ${ }^{13}$ who found reduced SR levels and/or elevated DAAO levels with decreased SR/DAAO ratio in patients with schizophrenia.

Regarding the severity of schizophrenia according to $D S M-5$, there was an insignificant difference in the serum levels of the studied biochemical parameters between patients with moderate and severe schizophrenia. However, 
estimation of the serum levels of the studied biochemical parameters in different clinical types of schizophrenia according to $D S M-I V$ revealed that the disorganized type of schizophrenia had the lowest level of D-ser and SR levels, together with the highest level of DAAO. On the contrary, the residual type had the highest level of D-ser and SR. In this context, Morita et $\mathrm{al}^{41}$ found less expression of the serine racemase receptors $(S R R)$ gene, which may result in less conversion of L-Ser to D-Ser and less activation of NMDA-Rs in patients with schizophrenia, especially in the paranoid subtype. Similarly, Goltsov et $\mathrm{al}^{42}$ showed that the paranoid subtype of schizophrenia was associated with dysregulation of SRR, which contributes to the pathophysiology of schizophrenia.

To the best of our knowledge, no previous studies could be traced in the literature regarding the sensitivity and specificity of D-Ser, SR and DAAO in the diagnosis of schizophrenia. In the present study, combined ROC curve for serum D-Ser and SR indicates that both have equal high positive and negative accuracy (positive predictive value $[\mathrm{PPV}]=100$ and negative predictive value $[\mathrm{NPV}]=100$ for both), which means that these biochemical markers are perfect as regards schizophrenia diagnosis. The best serum level cutoff points at which schizophrenia manifestations start to appear were $\leq 61.4 \mathrm{mg} / \mathrm{L}$ for D-Ser and $\leq 15.5 \mathrm{pg} / \mathrm{mL}$ for SR at a sensitivity of $100 \%$ and a specificity of $100 \%$ for both. Regarding the ROC curve for serum levels of DAAO, it is considered better positive than negative ( $P P V=91.8$ and NPV $=57.1$ ) in schizophrenia diagnosis beside the clinical correlation. The best serum level cutoff point at which schizophrenia manifestations start to appear was $>35.6 \mathrm{pg} / \mathrm{mL}$ at a sensitivity of $67 \%$ and a specificity of $88 \%$.

\section{Conclusion}

The data of the present study collectively demonstrate that reduced serum levels of D-Ser and disturbance of its metabolizing enzymes (SR and DAAO) may play an important role in the pathogenesis of schizophrenia. This may shed new light on nontraditional strategies for the future medical treatments of schizophrenia, through normalization of D-Ser metabolism, especially on the genetic levels.

\section{Study limitations}

The role of other factors such as the type of antipsychotics used, the dosage of antipsychotics (in chlorpromazine equivalent) on the day of biochemical assessment of D-Ser and its metabolizing enzymes (SR and DAAO), body mass index, cigarette smoking and dietary protein intake could not be taken into consideration in the statistical analysis as possible confounders.

\section{Disclosure}

The authors report no conflicts of interest in this work.

\section{References}

1. Northoff G. Resting state activity and the "stream of consciousness" in schizophrenia - neurophenomenal hypotheses. Schizophr Bull. 2015; 41(1):280-290

2. Collin L, Bindra J, Raju M, Gillberg C, Minnis H. Facial emotion recognition in child psychiatry: a systematic review. Res Dev Disabil. 2013; 34(5):1505-1520.

3. Anticevic A, Murray JD, Barch DM. Bridging levels of understanding in schizophrenia through computational modeling. Clin Psychol Sci. 2015;3(3):433-459.

4. Elvevag B, Goldberg TE. Cognitive impairment in schizophrenia is the core of the disorder. World Health Report 2001. Mental health: new understanding, new hope. Geneva: World Health Organization. Crit Rev Neurobiol. 2000;14(1):1-21.

5. Javitt DC. Twenty-five years of glutamate in schizophrenia: are we there yet? Schizophr Bull. 2012;38(5):911-913.

6. Ohgi Y, Futamura T, Hashimoto K. Glutamate signaling in synaptogenesis and NMDA receptors as potential therapeutic targets for psychiatric disorders. Curr Mol Med. 2015;15(3):206-221.

7. Jadi MP, Behrens MM, Sejnowski TJ. Abnormal gamma oscillations in N-methyl-D-aspartate receptor hypofunction models of schizophrenia. Biol Psychiatry. 2016;79(9):716-726.

8. Javitt DC, Zukin SR, Heresco-Levy U, Umbricht D. Has an angel shown the way? Etiological and therapeutic implications of the PCP/NMDA model of schizophrenia. Schizophr Bull. 2012;38(5):958-966.

9. Hashimoto K, Engberg G, Shimizu E, Nordin C, Lindström LH, Iyo M. Reduced D-serine to total serine ratio in the cerebrospinal fluid of drug naive schizophrenic patients. Prog Neuropsychopharmacol Biol Psychiatry. 2005;29(5):767-769.

10. Lane HY, Lin CH, Huang YJ, Liao CH, Chang YC, Tsai GE. A randomized, double-blind, placebo-controlled comparison study of sarcosine (N-methylglycine) and D-serine add-on treatment for schizophrenia. Int J Neuropsychopharmacol. 2010;13(4):451-460.

11. Singh SP, Singh V. Meta-analysis of the efficacy of adjunctive NMDA receptor modulators in chronic schizophrenia. CNS Drugs. 2011; 25(10):859-885.

12. Verrall L, Walker M, Rawlings N, et al. D-Amino acid oxidase and serine racemase in human brain: normal distribution and altered expression in schizophrenia. Eur J Neurosci. 2007;26(6):1657-1669.

13. Bendikov I, Nadri C, Amar S, et al. A CSF and postmortem brain study of d-serine metabolic parameters in schizophrenia. Schizophr Res. 2007;90(1):41-51.

14. Schell MJ. The N-methyl-d-aspartate receptor glycine site and d-serine metabolism: an evolutionary perspective. Philos Trans $R$ Soc Lond B Biol Sci. 2004;359(1446):943-964.

15. De Koning TJ, Klomp LW. Serine-deficiency syndromes. Curr Opin Neurol. 2004;17(2):197-204.

16. Schell MJ, Molliver ME, Snyder SH. D-serine, an endogenous synaptic modulator: localization to astrocytes and glutamate-stimulated release. Proc Natl Acad Sci U S A. 1995;92(9):3948-3952.

17. Horiike K, Tojo H, Arai R, Nozaki M, Maeda T. D-amino-acid oxidase is confined to the lower brain stem and cerebellum in rat brain: regional differentiation of astrocytes. Brain Res. 1994;652(2):297-303.

18. Nishikawa T. Metabolism and functional roles of endogenous D-serine in mammalian brains. Biol Pharm Bull. 2005;28(9):1561-1565.

19. Liu R, Dang W, Du Y, Zhou Q, Liu Z, Jiao K. Correlation of functional GRIN2A gene promoter polymorphisms with schizophrenia and serum d-serine levels. Gene. 2015;568(1):25-30. 
20. Gonzalez-Burgos G, Lewis DA. NMDA receptor hypofunction, parvalbumin-positive neurons, and cortical gamma oscillations in schizophrenia. Schizophr Bull. 2012;38(5):950-957.

21. Itokawa M, Yamada K, Iwayama-Shigeno Y, Ishitsuka Y, Detera-Wadleigh S, Yoshikawa T. Genetic analysis of a functional GRIN2A promoter (GT)n repeat in bipolar disorder pedigrees in humans. Neurosci Lett. 2003;345(1):53-56.

22. Van der Werf M, Hanssen M, Köhler S, et al. Systematic review and collaborative recalculation of 133,693 incident cases of schizophrenia. Psychol Med. 2014;44(1):9-16.

23. Fretland RA, Andersson S, Sundet K, Andreassen OA, Melle I, Vaskinn A. Theory of mind in schizophrenia: error types and associations with symptoms. Schizophr Res. 2015;162(1-3):42-46.

24. Ozeki Y, Sekine M, Fujii K, et al. Phosphoserine phosphatase activity is elevated and correlates negatively with plasma D-serine concentration in patients with schizophrenia. Psychiatry Res. 2016;237:344-350.

25. Pawełczyk T, Kołodziej-Kowalska E, Pawełczyk A, Rabe-Jabłon'ska J. Effectiveness and clinical predictors of response to combined ECT and antipsychotic therapy in patients with treatment-resistant schizophrenia and dominant negative symptoms. Psychiatry Res. 2014;220(1):175-180.

26. Tsai G, Yang P, Chung LC, Lange N, Coyle JT. D-serine added to antipsychotics for the treatment of schizophrenia. Biol Psychiatry. 1998; 44(11):1081-1089.

27. Heresco-Levy U, Javitt DC, Ebstein R, et al. D-serine efficacy as add-on pharmacotherapy to risperidone and olanzapine for treatment-refractory schizophrenia. Biol Psychiatry. 2005;57(6):577-585.

28. Levin R, Dor-Abarbanel AE, Edelman S, et al. Behavioral and cognitive effects of the N-methyl-D-aspartate receptor co-agonist D-serine in healthy humans: initial findings. J Psychiatr Res. 2015;61:188-195.

29. Hashimoto K, Fukushima T, Shimizu E, et al. Decreased serum levels of D-serine in patients with schizophrenia: evidence in support of the N-methyl-D-aspartate receptor hypofunction hypothesis of schizophrenia. Arch Gen Psychiatry. 2003;60(6):572-576.

30. Yamada K, Ohnishi T, Hashimoto K, et al. Identification of multiple serine racemase (SRR) mRNA isoforms and genetic analyses of SRR and DAO in schizophrenia and D-serine levels. Biol Psychiatry. 2005; 57(12):1493-1503

31. Mothet JP, Rouaud E, Sinet PM, et al. A critical role for the glial-derived neuromodulator D-serine in the age-related deficits of cellular mechanisms of learning and memory. Aging Cell. 2006;5(3):267-274.
32. Ohnuma T, Arai H. Significance of NMDA receptor-related glutamatergic amino acid levels in peripheral blood of patients with schizophrenia. Prog Neuropsychopharmacol Biol Psychiatry. 2011;35(1):29-39.

33. Brouwer A, Luykx JJ, van Boxmeer L, Bakker SC, Kahn RS. NMDAreceptor coagonists in serum, plasma, and cerebrospinal fluid of schizophrenia patients: a meta-analysis of case-control studies. Neurosci Biobehav Rev. 2013;37(8):1587-1596.

34. Mothet JP, Parent AT, Wolosker H, et al. D-serine is an endogenous ligand for the glycine site of the N-methyl-D-aspartate receptor. Proc Natl Acad Sci U S A. 2000;97(9):4926-4931.

35. Chumakov I, Blumenfeld M, Guerassimenko O, et al. Genetic and physiological data implicating the new human gene G72 and the gene for D-amino acid oxidase in schizophrenia. Proc Natl Acad Sci U S A. 2002; 99(21):13675-13680.

36. Boks MP, Rietkerk T, Van De Beek MH, Sommer IE, De Koning TJ, Kahn RS. Reviewing the role of the genes G72 and DAAO in glutamate neurotransmission in schizophrenia. Eur Neuropsychopharmacol. 2007;17(9):567-572.

37. Madeira C, Freitas ME, Vargas-Lopes C, Wolosker H, Panizzutti R. Increased brain D-amino acid oxidase (DAAO) activity in schizophrenia. Schizophr Res. 2008;101(1-3):76-83.

38. Burnet PWJ, Eastwood SL, Bristow GC, et al. D-Amino acid oxidase (DAO) activity and expression are increased in schizophrenia. Mol Psychiatry. 2008;13(7):658.

39. Nitoker N, Major DT. Understanding the reaction mechanism and intermediate stabilization in mammalian serine racemase using multiscale quantum classical simulations. Biochemistry. 2014;54(2):516-527.

40. Calcia MA, Madeira C, Alheira FV, et al. Plasma levels of D-serine in Brazilian individuals with schizophrenia. Schizophr Res. 2012; 142(1-3):83-87.

41. Morita Y, Ujike H, Tanaka Y, et al. A genetic variant of the serine racemase gene is associated with schizophrenia. Biol Psychiatry. 2007; 61(10):1200-1203.

42. Goltsov AY, Loseva JG, Andreeva TV, et al. Polymorphism in the $5^{\prime}$-promoter region of serine racemase gene in schizophrenia. Mol Psychiatry. 2006;11(4):325-326.
Neuropsychiatric Disease and Treatment

\section{Publish your work in this journal}

Neuropsychiatric Disease and Treatment is an international, peerreviewed journal of clinical therapeutics and pharmacology focusing on concise rapid reporting of clinical or pre-clinical studies on a range of neuropsychiatric and neurological disorders. This journal is indexed on PubMed Central, the 'PsycINFO' database and CAS,

\section{Dovepress}

and is the official journal of The International Neuropsychiatric Association (INA). The manuscript management system is completely online and includes a very quick and fair peer-review system, which is all easy to use. Visit http://www.dovepress.com/testimonials.php to read real quotes from published authors. 